\title{
"Optimal surfactant delivery protocol using the bovine lipid extract surfactant: a quality improvement study"
}

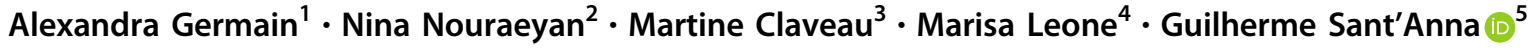

Received: 10 May 2020 / Revised: 21 August 2020 / Accepted: 24 September 2020 / Published online: 3 October 2020

(c) The Author(s), under exclusive licence to Springer Nature America, Inc. 2020

\begin{abstract}
Importance Episodes of severe airway obstruction (SAO) are reported during surfactant administration.

Objective To evaluate adherence to and impact of a surfactant protocol on adverse events.

Methods An evidence-based protocol for surfactant administration was developed (2011), implemented (2012) and reimplemented (2014), including three major steps: lung recruitment, manual bagging, and bolus instillation. Three epochs were evaluated: $E_{0}$ (2010), $E_{1}(2015)$ and $E_{2}$ (2018). Adherence was defined as compliance with all steps. Adverse events such as hypoxia $(<80 \%)$ and severe airway obstruction $(\mathrm{SAO})$ were investigated.

Results 197 infants (246 administrations) were included: $E_{0} 81$ (110), $E_{1} 52$ (63), and $E_{2} 64$ (73). Adherence improved from $49 \%\left(\mathrm{E}_{1}\right)$ to $67 \%\left(E_{2}\right)$. Full adherence to protocol significantly decreased SAO from $26 \%$ to $1.25 \%\left(E_{2} ; p<0.005\right)$ and hypoxia/bradycardia events ( 5 to $0 \% E_{2} ; p<0.005$ ), without any side effects.

Conclusions Adherence to a surfactant administration protocol improved over time and significantly decreased important adverse events.
\end{abstract}

\section{Introduction}

Even though surfactant has been effectively used in neonates for several decades [1-4], the best instillation technique for optimal delivery into the pulmonary airways is still unclear. This is quite noteworthy since administration technique, to assure homogenous distribution, is recognized as a major component of therapy efficacy [5-8]. In addition,

Supplementary information The online version of this article (https:// doi.org/10.1038/s41372-020-00846-1) contains supplementary material, which is available to authorized users.

Guilherme Sant'Anna

guilherme.santanna@mcgill.ca

1 McGill University, Montreal, QC, Canada

2 Department of Pediatrics, Neonatal Division, Jewish General Hospital, McGill University Health Center, Montreal, QC, Canada

3 Department of Pediatrics, Neonatal Division, Montreal Children's Hospital, McGill University Health Center, Montreal, QC, Canada

4 Department of Pediatrics, Montreal Children's Hospital, McGill University Health Center, Montreal, QC, Canada

5 Department of Pediatrics, Neonatal Division, Montreal Children's Hospital, McGill University Health Center, Montreal, QC, Canada it is unknown if the technique should change based on the population being treated and drug composition and/or volume; and how this can affect distribution.

The Bovine Lipid Extract Surfactant $\left(\right.$ BLES $^{\circledast}$ Biochemicals Inc., London, Canada) has $27 \mathrm{mg}$ of phospholipid $/ \mathrm{mL}$ and should be administered at a dose of $5 \mathrm{~mL} / \mathrm{kg}(135 \mathrm{mg}$ of phospholipid) [9]. This low cost surfactant has been used since 1983 but some adverse events were reported during instillation in infants with birth weight $<1000 \mathrm{~g}$ [10]. The most stark was the occurrence of severe airway obstruction (SAO) during or immediately after delivery, which lead to significant hypoxia, hemodynamic changes, and ultimately the need of endotracheal tube (ETT) removal and reintubation. Indeed, a number of these events were observed in our unit during the administration of bovine lipid extract surfactant. The clear reason why these events occurred is unknown but in extremely preterm infants, delivery of surfactant without disconnection from the ventilator was associated with a high incidence of airway obstruction [11]. Therefore, adverse events during surfactant delivery might be related to the technique, and type of surfactant and/or targeted population.

With the increased and effective use of non-invasive respiratory support at birth, surfactant administration is now mostly used in smaller and more immature preterm infants, a population under higher risks of complication. Therefore, 


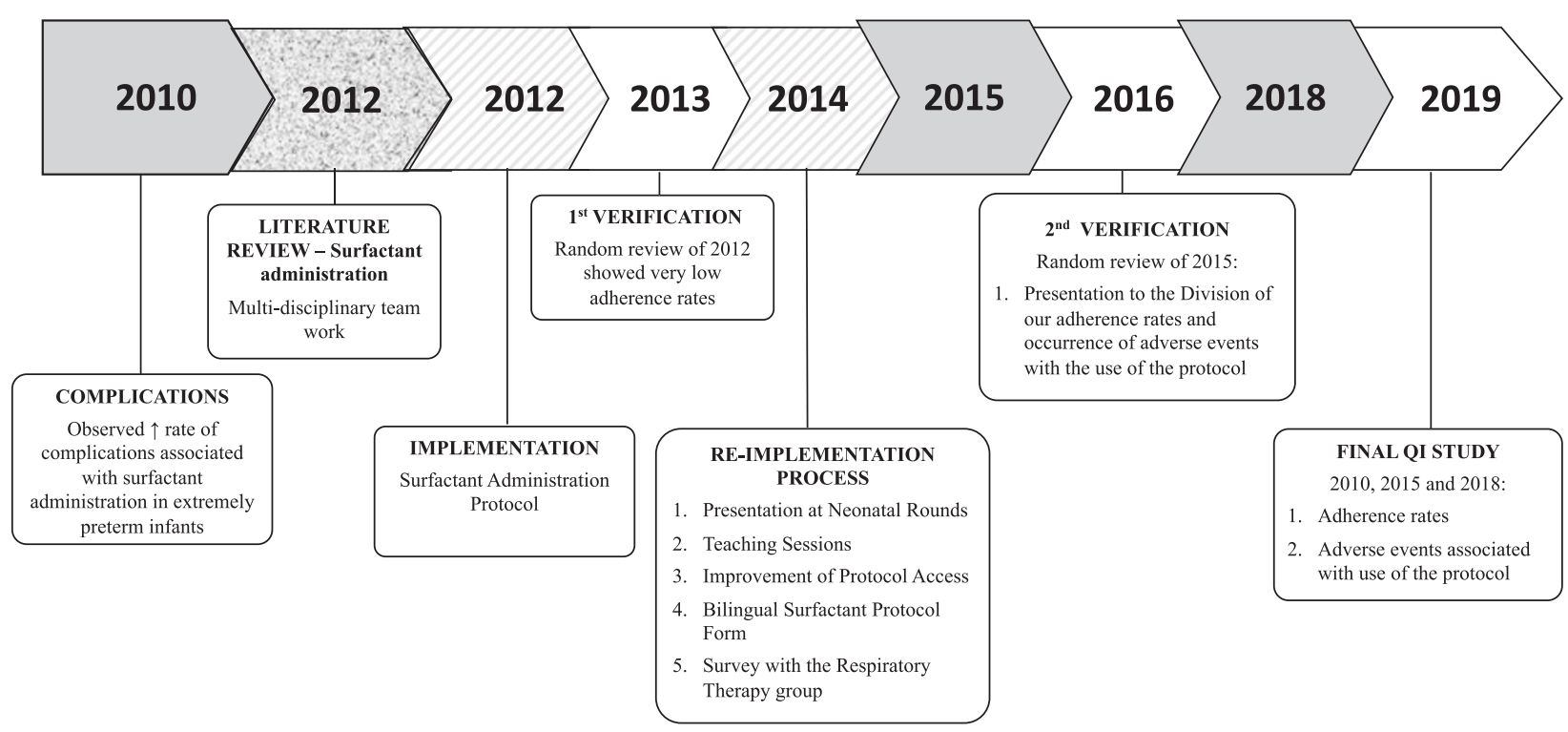

Fig. 1 Surfactant protocol implementation and re-implementation timeline. The interventions performed are described for each year. The final QI evaluation was done using the years of 2010, 2015 and 2018.

a few years ago we performed a review of the literature and identified three important aspects for optimal surfactant delivery into the pulmonary airways: use of large volumes by bolus administration, manual bagging, and recruitment of the lungs prior to instillation [12]. This led to the implementation of a bovine lipid extract surfactant administration protocol in our unit with the aim to streamline administration techniques and decrease rates of adverse events, notably SAOs. Thus, the primary objective of the quality improvement (QI) study is to evaluate the occurrence of severe airway obstruction events.

\section{Methods}

\section{Context}

The administration of the bovine lipid extract surfactant in extremely preterm infants has been reported as associated with adverse events such as SAOs. In 2010, we observed a rate of $26 \%$ of SAO in infants with birth weight $(\mathrm{BW})<$ $1250 \mathrm{~g}$ that received surfactant. This finding combined with inconsistent surfactant administration techniques prompted the development of an evidence-based protocol for surfactant administration in our unit. The aim was to decrease SAO events from 26 to $2 \%$ over a 2 -years period following protocol implementation. In this QI study we assessed all steps involved during the overall period of 8 years (2011-2019).

\section{Population and site}

Infants $<32$ weeks of gestational age (GA) treated with surfactant therapy at the Royal Victoria Hospital or
Montreal Children's Hospital during the study periods, were analyzed. Patients were identified using the local Canadian Neonatal Network databases. Infants with a genetic surfactant deficiency syndrome, complex genetic syndromes, or infants where surfactant was given at referring centers or during transport, were excluded.

\section{Planning the interventions}

The surfactant administration protocol was developed during the year of 2011 by a multidisciplinary committee based on the best-quality evidence available. (Fig. 1) Details of the protocol have been published [12] and are publicly available (https://www.cjrt.ca/wp-content/uploads/surfactant-a dministration-in-neonates-a-review-of-delivery-methods.

pdf). Briefly, it includes surfactant administration criteria and guidance for all phases of drug delivery (before, during and after administration). Of note, a pre-recruitment maneuver using a positive end expiratory pressure of $8 \mathrm{~cm} \mathrm{H}_{2} \mathrm{O}$ for a minimum of $30 \mathrm{~s}$ should be performed without changing the tidal volume of $4-5 \mathrm{~mL} / \mathrm{kg}$ used during the assisted control volume guaranteed mode of ventilation. Furthermore, surfactant is then given as bolus, divided into two equal aliquots, and while providing manual ventilation with the flow-inflating bag or a T-piece during drug instillation. Vital signs are recorded carefully by both the bedside nurse and the respiratory therapist and no suctioning of the endotracheal tube was to occur until $2 \mathrm{~h}$ post administration.

\section{Planning the study of the interventions}

In this QI study, in order to evaluate the impact of the surfactant administration protocol three epochs $(E)$ were 
established: $E_{0}=$ before surfactant protocol (JanuaryDecember 2010); $E_{1}=$ after protocol development, implementation, and re-implementation (January-December 2015) and $E_{2}=3-4$ years after protocol re-implementation (January-December 2018).

\section{Description of measures}

The outcome measure of the study was the number of SAO events. Process measure was adherence to the protocol and balancing measures were the occurrence of adverse events associated with surfactant administration such as pneumothorax, pulmonary hypertension, and episodes of bradycardia and desaturations. All information was extracted from medical records but for $E_{1}$ and $E_{2}$ data was also obtained from a specially designed form filled by respiratory therapy during drug administration.

The following variables were also extracted: GA, BW, gender, singleton status, antenatal steroid therapy (complete or incomplete), mode of delivery, maternal use of antibiotics, Apgar scores at 1 and $5 \mathrm{~min}$, positive pressure ventilation requirements and need for intubation at delivery.

\section{Definitions}

The lack of compliance to any of the three steps established in the protocol was defined as non-adherence and unknown adherence was defined as absence to fully fill the form. Minor events were defined as hypoxia (oxygen saturation $<80 \%$ ) and/or bradycardia (<100 bpm) and major events as pulmonary hypertension (pre/post $\mathrm{SpO}_{2}$ difference greater than $5-10 \%$ checked in the surfactant form by the respiratory therapist or diagnosed by the medical team within $48 \mathrm{~h}$ after procedure), pulmonary hemorrhage, pneumothorax, and SAO. SAO was defined as an episode of hypoxia ( $<80 \%$ saturation)/bradycardia $(<100 \mathrm{bpm})$ AND any of the following: (a) need to increase PIP, (b) need to suction the ETT, (c) lack of chest rise or (d) need for ETT exchange. Major complications were reported only if they occurred within a certain timeframe to ensure causality: (a) pulmonary hemorrhage and pulmonary hypertension within $48 \mathrm{~h}$ after the procedure; (b) pneumothorax within $24 \mathrm{~h}$ after the procedure and (c) SAOs during or immediately at the end of the procedure.

\section{Statistical analysis}

Categorical variables are expressed as counts and percentages and continuous variables as mean \pm standard deviation (SD). The Chi-square test and the Fischer exact test were used for categorical variables and the Student $t$ test for continuous variables. All results were analyzed for infants that received surfactant with full protocol adherence during the study period and for the overall population. Statistical analysis was performed using the software SPSS (Statistical Package for the Social Sciences). A $p$ value $<0.05$ was considered as statistically significant.

\section{Ethical considerations}

The protocol development and implementation followed all steps of the McGill University Health Center policies and was approved for implementation and use in 2012. The present study was approved by the research ethics board of the institution.

\section{Plan-Do-Study-Act 1 (January-December 2010)}

A number of complications were reported by different neonatologist, respiratory therapists, and neonatal nurse practioners during the administration of the bovine lipid extract surfactant in the delivery room or the neonatal intensive care unit. Cases were discussed in morbidity rounds and given lack of consistence in administration techniques used and a previous study from Canada describing similar events [10], general consensus was attained for the need to develop an evidence-based protocol for surfactant administration in our unit (Fig. 1).

\section{Plan-Do-Study-Act 2 (January 2011-December 2014)}

The protocol was developed in 2011 and implemented in 2012. In 2013, a random review for the 2012 year revealed very low adherence rates. Thus, during the year of 2014 a reimplementation process was undertaken using several steps: presentation of the protocol at Neonatal Grand Rounds, teaching of the details and reasons for the three main steps to all respiratory therapists and neonatologists, improvement in protocol access at bedside and development of a surfactant administration form (bilingual) to be used during each administration. (Appendix 1) This form included a stepwise checklist to be filled by the respiratory therapists and a comprehensive description of the protocol on its back side. The form remained at bedside for $24 \mathrm{~h}$ after each surfactant administration event to ensure that information of any adverse complication was properly recorded. A carbon copy of the form was collected afterwards and kept with the respiratory therapy manager $(\mathrm{ML})$; the original was left in the medical record. In addition, an internal survey with our respiratory therapy group was done to assure their knowledge on the protocol, specifically the three main steps.

\section{Plan-Do-Study-Act 3 (January 2016-October 2019)}

In 2016, a second audit on the use of our surfactant administration protocol was done for the year of 2015 . 
Fig. 2 Flow diagram of the population. $\mathrm{SAE}=$ surfactant administration events.

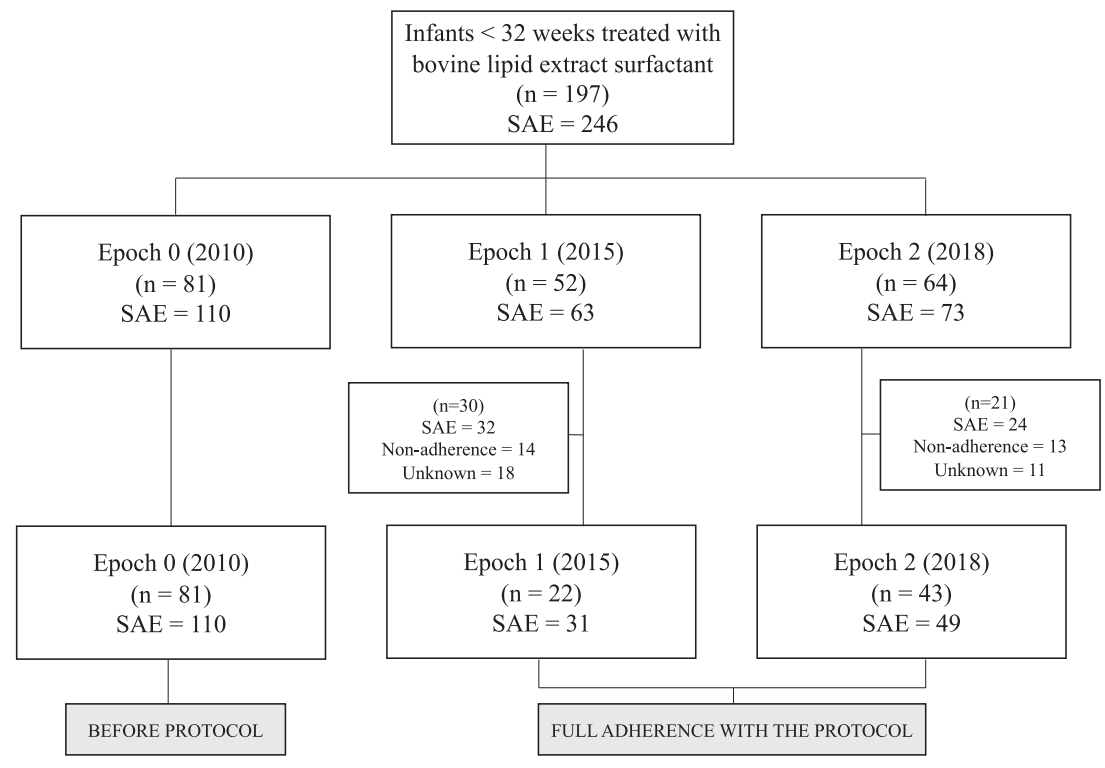

Adherence rates and conclusions were then presented along with results of the internal survey done in 2014 to highlight the areas that could be improved. No other implementation process took place after this point. Finally, in 2019 this QI study was designed to evaluate adherence to the protocol and rates of adverse events (Fig. 1).

\section{Results}

The initial steps of the intervention and their evolution over time are included in Fig. 1. During the three epochs selected a total 197 infants received 246 surfactant administration events (Fig. 2): $E_{0}=81$ infants (110 events), $E_{1}=52$ infants (63 events), and $E_{2}=64$ patients ( 73 events). In both $E_{1}$ and $E_{2}$, infants were of significantly lower GA and BW, had lower Apgar scores at 1 and $5 \mathrm{~min}$, and required more positive pressure ventilation despite improved usage of antenatal steroid therapy when compared to $E_{0}$ (Table 1 ).

\section{Process measure-adherence to the protocol}

Protocol adherence increased over time, from $49 \%\left(E_{1}\right)$ to $67 \%\left(E_{2}\right)$ (Appendix 2). The reasons for lack of adherence were: $E_{1}=14$ events did not follow the protocol and 18 unknown adherence and $E_{2}=13$ events did not follow protocol and 11 unknown adherences (Table 2).

\section{Outcome and balancing measures-SAO and other adverse events associated with surfactant administration}

Full adherence to the protocol. There was a significant decrease in SAO events in infants that received surfactant in
Table 1 Population demographics.

\begin{tabular}{llll}
\hline & $E_{0}(n=81)$ & $E_{1}(n=52)$ & $E_{2}(n=64)$ \\
\hline Gestational age (weeks) & $29.8 \pm 4.8$ & $28.6 \pm 3.5^{*}$ & $28.5 \pm 4.1^{*}$ \\
Birthweight $(\mathrm{g})$ & $1583 \pm 956$ & $1234 \pm 648^{*}$ & $1297 \pm 771^{*}$ \\
Gestational age $<32$ weeks & $52(64)$ & $42(81)^{*}$ & $52(81)^{*}$ \\
Male & $53(65)$ & $27(52)$ & $39(61)$ \\
Singleton & $65(80)$ & $44(85)$ & $47(73)$ \\
Outborn & $31(38)$ & $5(10)^{*}$ & $9(14)^{*}$ \\
Antenatal steroids-complete & $27(33)$ & $29(56)^{*}$ & $34(55)^{*}$ \\
Antenatal steroids—none & $32(39.5)$ & $8(15)^{*}$ & $13(20)^{*}$ \\
Antibiotics (<24 h prior delivery) & $43(53)$ & $36(69)$ & $40(62.5)$ \\
Vaginal delivery & $34(42)$ & $23(44)$ & $22(34)$ \\
Cesarean delivery & $47(58)$ & $29(56)$ & $42(66)$ \\
Apgar 1 min & $5.3 \pm 2.7$ & $3.8 \pm 2.0^{*}$ & $3.92 \pm 2.7^{*}$ \\
Apgar 5 min & $7.0 \pm 2.2$ & $5.7 \pm 1.9^{*}$ & $5.79 \pm 2.1^{*}$ \\
Positive pressure ventilation & $55(68)$ & $48(94)^{*}$ & $61(95)^{*}$ \\
Intubation & $41(51)$ & $28(54)$ & $30(47)$ \\
Surfactant administration events & 110 & 63 & 73 \\
\hline
\end{tabular}

$E=$ epoch year; $E_{0}=2010, E_{1}=2015$, and $E_{2}=2018$. Results are expressed as $n(\%)$ or mean \pm SD.

* $p<0.05$ for $E_{0}$ vs $E_{1}$ and $E_{0}$ vs $E_{2}$.

full adherence with the protocol (Table 2 and Fig. 3). Indeed, during $E_{1}$ and $E_{2}$ a total of 80 administrations followed the protocol with only one SAO event (1.25\%). Also, no episodes of hypoxia/bradycardia and pulmonary hypertension, and no additional side effects were detected. No case of pneumothorax occurred during $E_{0}$ and only two cases $(2.5 \%)$ were noted during $E_{1}$ and $E_{2}$.

Overall population. Following protocol implementation fewer (but not significant) minor events were observed during $E_{1}$ and $E_{2}$. Importantly, a significant reduction in SAOs was noted: $E_{0}=29$ vs $E_{1}=2(p<0.005)$ and $E_{0}=29$ vs $E_{2}=2(p<0.005)$. Both SAO events in $E_{1}$ and one event during $E_{2}$ occurred in infants with unknown protocol 
adherence. In fact, the incidence of SAOs with unknown full adherence was $14 \%\left(E_{1}\right)$ and $8 \%\left(E_{2}\right)$. Two cases of pneumothorax were noted during $E_{1}$ and $E_{2}$ when the protocol was not followed. The details of all adverse events for the overall population are described in Appendix 3.

Table 2 Adherence to the protocol and adverse events with full adherence.

$$
E_{0}(n=110) \quad E_{1}(n=63) \quad E_{2}(n=73)
$$

Protocol adherence

$\begin{array}{llll}\text { Full adherence (all 3 steps) } & - & 31(49) & 49(67) \\ \text { No-adherence } & - & 14(22) & 13(18) \\ \text { Unknown }^{\mathrm{a}} & - & 18(29) & 11(15) \\ \begin{array}{l}\text { Adverse Events } \\ \text { Major }\end{array} & (\boldsymbol{n}=\mathbf{1 1 0}) & (\boldsymbol{n}=\mathbf{3 1}) & (\boldsymbol{n}=\mathbf{4 9}) \\ \begin{array}{l}\text { Severe airway obstruction } \\ \text { Pneumothorax }\end{array} & 29(26) & - & 1(2)^{*} \\ \text { Pulmonary hemorrhage } & 2(2) & 1(3) & 1(2) \\ \text { Pulmonary hypertension } & 1(1) & - & - \\ \text { Minor } & & & - \\ \text { Hypoxia } & 8(7) & 4(13) & 4(8) \\ \text { Bradycardia } & - & - & - \\ \text { Hypoxia and Bradycardia } & 6(5) & - & -\end{array}$

$E=$ epoch; $E_{0}=2010, \quad E_{1}=2015$, and $E_{2}=2018$. Results are expressed as $n(\%)$; .

${ }^{*} p<0.005$ for $E_{0}$ vs $E_{1}$ and $E_{2}$.

${ }^{a}$ Blank spaces in the surfactant administration form were categorized as unknown adherence.

\section{Discussion}

In this study, adherence to a standardized surfactant administration protocol increased over time and was associated with a significant decrease on the number of SAO and hypoxia/bradycardia events, when using the bovine lipid extract surfactant for treatment of respiratory distress syndrome. Importantly, this improvement was sustained over time and occurred in a population of lower GA and $\mathrm{BW}$.

Clinical protocols are important pathways used to implement evidence-based therapies and reduce unnecessary variations in practice [13, 14]. Indeed, protocols for respiratory care have been increasingly used by Canadian NICUs [15, 16]. However, compliance rates are generally reported as low (25-50\%) which can be improved by using of a multidisciplinary approach as done in our center [14]. Unfortunately, our study lacks precision on protocol adherence calculation since incomplete forms were classified as unknown. Thus, adherence rates could have been higher than the $67 \%$ reported on $E_{2}$. Nevertheless, it is important to highlight that higher adherence rates $(>90 \%)$ are possible but require a massive effort by institutions in their initial phases of implementation [17].

Despite the bovine lipid extract surfactant being a lowcost preparation used for several years, only six clinical studies were performed: four randomized controlled trials (RCT) [9, 18-20], one prospective observational study [10] and one retrospective single center analysis [21]. Unfortunately, except for one study [10], details on the surfactant
Fig. 3 Severe airways obstruction events over time. $\mathrm{SAO}=$ Severe airway obstruction. Each point represents the number of SAO events for the periods of January-March, April-June, July-September and October-December; for all Epochs of the study. The box shows the number of surfactant administration events and percentage of SAO for each specific period. In Epochs 1 and 2 only surfactant administration events with full adherence to the protocol were included.

\section{Severe Airway Obstruction events overtime, by quarter}

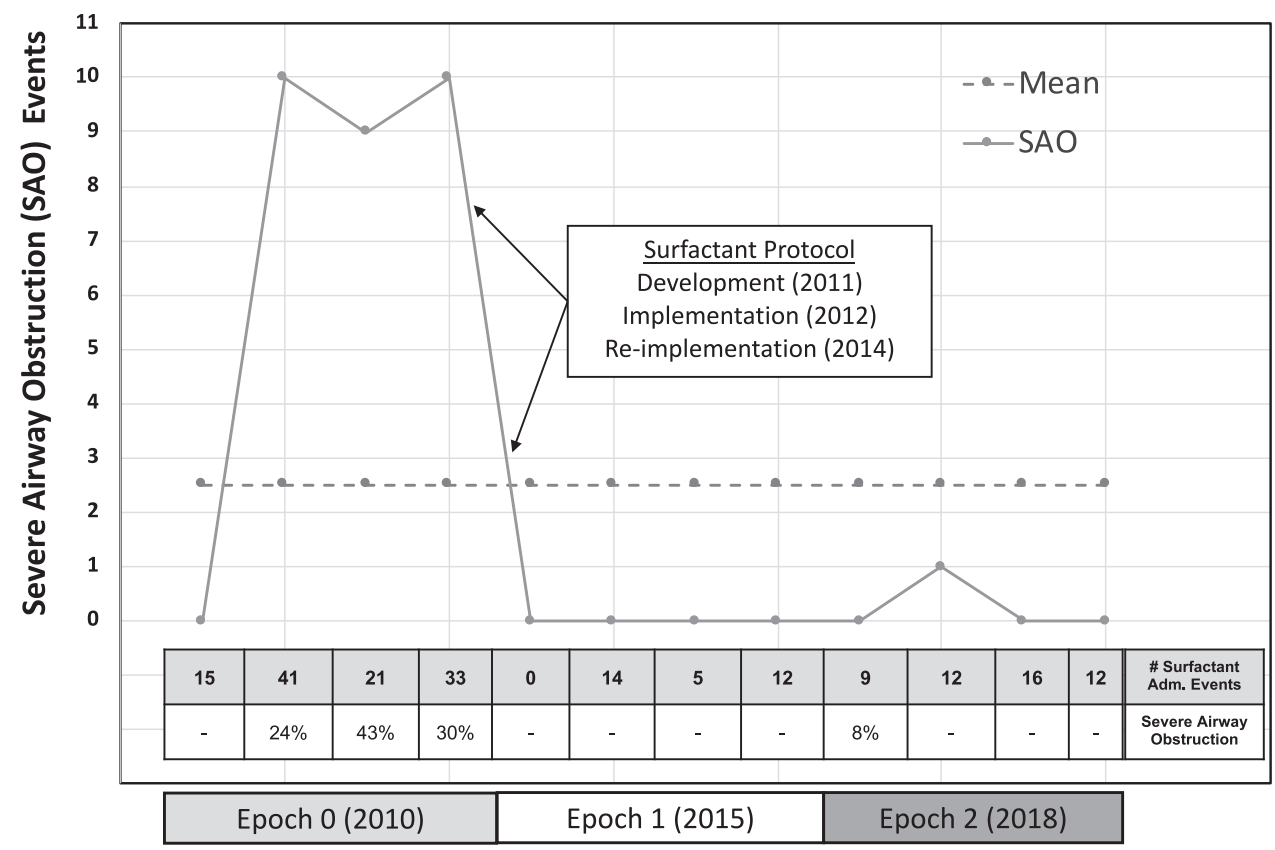


administration technique is not provided and reports on major adverse effects were quite variable. The only large multicenter trial (unpublished) compared the $\mathrm{BLES}^{\circledR}$ with colfosceril palmitate (Exosurf ${ }^{\circledR}$ Neonatal; Glaxo Wellcome). A total of 568 infants of significant higher GA and BW received $\mathrm{BLES}^{\circledR}$ and a $6 \%$ incidence of any type of ETT obstruction (not defined) was reported [9]. In 2005, Lam et al. compared BLES ${ }^{\circledR}$ with a bovine lung extract (Berac$\tan t^{\circledast}$, Ross Laboratories, Columbus, $\mathrm{OH}$ ) and no adverse events were described with both preparations [18]. A recent small multicenter Canadian RCT compared BLES ${ }^{\circledR}$ with an extract of natural porcine lung surfactant (Curosurf $^{\circledR}$, Chiesi Pharmaceuticals, Parma, Italy) [19]. Surfactant was administered by using one or two aliquots instilled as bolus and five episodes $(11 \%)$ of SAO occurred only in infants who received $\mathrm{BLES}^{\circledR}$. Unfortunately, details on the administration technique/protocol were not described [19]. In 2018, another RCT included 100 infants (median of 30 weeks of GA) and compared BLES ${ }^{\circledR}$ with a bovine lung extract $\left(\right.$ Beractant $\left.^{\circledR}\right)$. Again, no significant difference on complications was observed between the groups and no case of SAO was stated [20]. Altogether, these trials enrolled 692 infants and some type of ETT obstruction was reported in between 6 and $11 \%$ of infants treated with BLES $^{\circledR}$ [19].

A retrospective single center study done in Canada investigated the time to reach room air following BLES ${ }^{\circledR}$ administration in infants $<37$ weeks and no side effects were identified [21]. In the only prospective study, we described an incidence of $15 \%$ of SAO, mostly in extremely low birthweight infants $(83 \%)$, an incidence similar to the Canadian RCT [19]. In that study a non-evidence based surfactant administration protocol that included multiple aliquots, no disconnection from the ventilator, and no lung recruitment prior to instillation was used [10]. Thus, our administration protocol was modified to promote better lung distribution without adverse events while using the same surfactant preparation [12]. Surfactant was given after a quick lung recruitment maneuver $(30 \mathrm{~s})$ and by bolus into two aliquots, and manual bagging was done after instillation of each aliquot (Appendix 1). It is important to note that in the present study, the lung recruitment strategy prior to the first dose was not tested independent of the other interventions and the use of positive pressure prior to surfactant administration may be harm in infants who have not been exposed to antenatal steroids as previously demonstrated in animal studies. Interestingly, with this modified technique the number of SAO events significantly decreased on epochs $E_{1}$ and $E_{2}$ combined $(p<0.005)$. Indeed, only one SAO occurred in the 80 administrations performed in full adherence with the protocol. These rates of SAO are significantly lower than previously reported [10, 19], and demonstrate the critical role of surfactant delivery technique to these immature infants when using a preparation that requires high instillation volumes [9]. Indeed, during the years of 2015 and 2018, a SAO rate of $14 \%\left(E_{1}\right)$ and $8 \%$ $\left(E_{2}\right)$ was observed when adherence to the protocol was unknown; within the range reported by the literature. Full adherence to the protocol was also associated with a significant decrease in hypoxia/bradycardia events and no cases of pulmonary hypertension. Furthermore, when the protocol was fully followed only two cases of pneumothorax were detected $(2.5 \%)$, a rate lower than that observed in large RCTs where surfactant was only administered to immature infants that failed an initial conservative approach of non-invasive support from birth [1-3], as the case for $E_{1}$ and $E_{2}$.

The results of our study demonstrate that surfactant administration technique should consider the type of surfactant used and target population, as preparations using much lower administration volumes $(2.5 \mathrm{~mL} / \mathrm{kg})$ are effective and do not report such adverse events without using all the steps outlined here [1]. This is probably due to the favorable tridimensional anatomy of the preterm lungs for adequate drug distribution even at lower instillation volumes [22]. Therefore, neonatal units should implement local evidencebased protocols for surfactant administration including costs analyzes while ensuring optimal care. In our case, the cost of the bovine lipid extract surfactant is estimated between two to four times less expensive (per patient/kg) than the other two available preparations in Canada (data from 2019 obtained from IQVIA Solutions Canada Inc. and our Pharmacy Department).

The study reviewed a single center experience making difficult to ascertain generalizability of the work. Some other limitations were the inability to assure correct fulfilling of the surfactant form and missing data due to its retrospective nature. Thus, we analyzed outcomes with full protocol adherence and for the overall population. The study reviewed more than 200 administration events in a high-risk preterm population receiving a type of commonly used surfactant. Moreover, we used a nationally wellorganized database to capture all infants who received surfactant. In addition, by using the specifically designed forms for each surfactant administration, data related to complications was prospectively collected for several years allowing a more reliable analysis of adherence rates and adverse events. Indeed, this is the first study specifically investigating the impact of a standardized surfactant administration protocol on rates of adverse events when using a specific low-cost and effective surfactant.

\section{Conclusion}

Adherence to a bovine lipid extract surfactant evidencebased administration protocol improved over time and was 
associated with a significant decrease in the number of severe airway obstruction and hypoxia/bradycardia events. Importantly, this improvement was sustained over years while using a low-cost surfactant preparation despite treating a smaller and more immature population. Better adherence rates may further improve outcomes. Importantly, results of our study demonstrate that surfactant administration technique is an important variable related to adverse events and should be tailored to the type of surfactant and population treated. Future studies in this area should clearly define and report the technique used during surfactant administration.

Acknowledgements The authors would like to acknowledge all health care workers of the units for their support to the protocol development and implementation, and data recordings.

Funding AG was supported by the Kevric Summer Research Bursary from McGill University, and GS by research funds received from the Montreal Children's Foundation.

Author contributions AG-data acquisition, analysis, interpretation of data, drafting and revising of the manuscript, and final approval of the version to be published. NN-conception and design of the work; data acquisition, analysis and interpretation of data, drafting and revising of the manuscript, and final approval of the version to be published. ML-conception of the work; interpretation of data, drafting and revising of the, manuscript and final approval of the version to be published. MC - design of the work; data acquisition, interpretation of data, drafting and revising of the manuscript, and final approval of the version to be published. GS - conception and design of the work; data analysis and interpretation, drafting and revising of the manuscript, and final approval of the version to be published.

\section{Compliance with ethical standards}

Conflict of interest The authors declare that they have no conflict of interest.

Publisher's note Springer Nature remains neutral with regard to jurisdictional claims in published maps and institutional affiliations.

\section{References}

1. Sweet DG, Carnielli V, Greisen G, Hallman M, Ozek E, Te Pas A, et al. European consensus guidelines on the management of respiratory distress syndrome-2019 update. Neonatology. 2019;115: 432-50.

2. Ardell S, Pfister RH, Soll R. Animal derived surfactant extract versus protein free synthetic surfactant for the prevention and treatment of respiratory distress syndrome. Cochrane Database Syst Rev. 2015;8:CD000144.

3. Polin RA, Carlo WA.Committee on Fetus and Newborn Surfactant replacement therapy for preterm and term neonates with respiratory distress. Pediatrics. 2014;133:156-63. American Academy of Pediatrics.

4. Davis DJ, Barrington KJ, Canadian Paediatric Society, Fetus and Newborn Committee. Recommendations for neonatal surfactant therapy. Paediatr Child Health. 2005;10:109-16.
5. Jobe AH. Mechanisms to explain surfactant responses. Biol Neonate. 2006;89:298-302.

6. Fernandez-Ruanova MB, Alvarez FJ, Gastiasoro E, et al. Comparison of rapid bolus instillation with simplified slow administration of surfactant in lung lavaged rats. Pediatr Pulmonol. 1998;26:129-34.

7. Segerer H, van Gelder W, Angenent FW, et al. Pulmonary distribution and efficacy of exogenous surfactant in lung-lavaged rabbits are influenced by the instillation technique. Pediatr Res. 1993;34:490-4.

8. Ueda T, Ikegami M, Rider ED, Jobe AH. Distribution of surfactant and ventilation in surfactant-treated preterm lambs. J Appl Physiol. 1994;76:45-55.

9. Peliowski A. A randomized, controlled, double blinded multicenter trial to compare synthetic surfactant (Exosurf) with a bovine surfactant (Bovine Lipid Extract Surfactant) for the treatment of respiratory distress syndrome of the newborn. 2002. Product Monograph. https://blesbiochem.com/BLES-ProductMonograph.pdf

10. Tarawneh A, Kaczmarek J, Bottino MN, Sant'Anna GM. Severe airway obstruction during surfactant administration using a standardized protocol: a prospective, observational study. J Perinatol. 2012;32:270-5.

11. Wheeler KI, Davis PG, Kamlin CO, Morley CJ. Assist control volume guarantee ventilation during surfactant administration. Arch Dis Child Fetal Neonatal Ed. 2009;94:336-8.

12. Nouraeyan N, Lambrinakos-Raymond A, Leone M, Sant'Anna G. Surfactant administration in neonates: a review of delivery methods. Can J Respir Ther. 2014;50:91-5.

13. Meade MO, Ely EW. Protocols to improve the care of critically ill pediatric and adult patients. JAMA. 2002;288:2601-3.

14. Sant'Anna GM, Keszler M. Developing a neonatal unit ventilation protocol for the preterm baby. Early Hum Dev. 2012;88:925-9.

15. Shalish W, Anna GM. The use of mechanical ventilation protocols in Canadian neonatal intensive care units. Paediatr Child Health. 2015;20:e13-9.

16. Hermeto F, Bottino MN, Vaillancourt K, Sant'Anna GM. Implementation of a respiratory therapist-driven protocol for neonatal ventilation: impact on the premature population. Pediatrics. 2009;123:e907-16.

17. Ely EW, Bennett PA, Bowton DL, Murphy SM, Florance AM, Haponik EF. Large scale implementation of a respiratory therapist-driven protocol for ventilator weaning. Am J Respir Crit Care Med. 1999;159:439-46.

18. Lam BCC, Ng YK, Wong KY. Randomized trial comparing two natural surfactants (Survanta vs. bLES) for treatment of neonatal respiratory distress syndrome. Pediatr Pulmonol. 2005; 39:64-9.

19. Lemyre B, Fusch C, Schmölzer GM, Rouvinez Bouali N, Reddy D, Barrowman N, et al. Poractant alfa versus bovine lipid extract surfactant for infants 24 to $31+6$ weeks gestational age: a randomized controlled trial. PLoS One. 2017;12: $\mathrm{e} 0175922$.

20. Macooie AA, Fakour Z, Roanaghi P. Comparative evaluation of the effects of BLES and Survanta on treatment of respiratory distress syndrome in newborns. J Fam Med Prim Care. 2018;7:1063-7.

21. Stockley E, Valotaire R, Miller M, da Silva O. Effects of bovine lipid extract surfactant administration in preterm infants treated for respiratory distress syndrome. Health Sci Rep. 2018;1:e34.

22. Kazemi A, Louis B, Isabey D, Nieman GF, Gatto LA, Satalin J, et al. Surfactant delivery in rat lungs: comparing 3D geometrical simulation model with experimental instillation. PLoS Comput Biol. 2019;15:e1007408. 